ARMS-71.6.2

Distribution Category UC-41

\title{
Aerial Radiological Measuring Survey of the Prairie Island Nuclear Generating Plant September 1971
}

\author{
EG\&G, Inc., Las Vegas, Nevada
}

This report is pary of a series on the continuing activities of the Aerial Radiological Measuring System operated for the U. S. Atomic Energy Commission. The ARMS program is managed by the Division of Operational Safety and is a cooperafuve effort among various offices and divisions of the Commission. 


\section{DISCLAIMER}

This report was prepared as an account of work sponsored by an agency of the United States Government. Neither the United States Government nor any agency Thereof, nor any of their employees, makes any warranty, express or implied, or assumes any legal liability or responsibility for the accuracy, completeness, or usefulness of any information, apparatus, product, or process disclosed, or represents that its use would not infringe privately owned rights. Reference herein to any specific commercial product, process, or service by trade name, trademark, manufacturer, or otherwise does not necessarily constitute or imply its endorsement, recommendation, or favoring by the United States Government or any agency thereof. The views and opinions of authors expressed herein do not necessarily state or reflect those of the United States Government or any agency thereof. 


\section{DISCLAIMER}

Portions of this document may be illegible in electronic image products. Images are produced from the best available original document. 


\section{ABSTRACT}

The Aerial Radiological Measuring System (ARMS) was used to survey the area surrounding the Prairie Island Nuclear Generating Plant during September 1971, prior to reactor start-up. The survey measured terrestrial gamma radiation.

A high-sensitivity detection system collected gamma-ray spectral and gross-count data. The data were then computer processed into a map of an 800 square mile area showing isoexposure contours three feet above the ground. Exposure rates and isotopes identified are consistent with normal terrestrial background radiation. 


\section{CONTENTS}

1. INTRODUCTION.

1.1 Identification of Surveyed Plant and Area . . 1

1.2 ARMS Program . . . . . . . . 1

1.3 ARMS Equipment and Procedures . . . . 1

1.4 Reduction and Presentation of Data . . . . 4

2. REACTOR AND SITE CHARACTERISTICS . . . . 5

2.1 Reactor Characteristics . . . . . . 5

2.2 Site Area Characteristics . . . . . . . 6

3. SURVEY PLAN . . . . . . . . . . 8

3.1 Specification of Flight Lines . . . . . 8

3.2 Coordination with Local Authorities. . . . 8

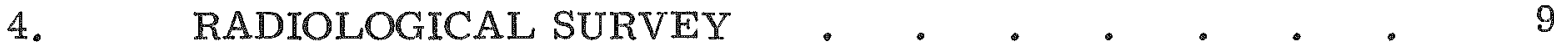

4. 1 Survey Missions . . . . . . . . 9

4.2 Gross-Count Data. . . . . . . ..

4.3 Spectral Data. . . . . . . . . . 9

5. SUMMARY AND CONCLUSIONS . . . . . . 14 


\section{INTRODUCTION}

\subsection{Identification of Surveyed Plant and Area}

The Aerial Radiological Measuring System (ARMS) (Ref. 1) operated by EG\&G, Inc. Las Vegas, Nevada, for the U. S. A tomic Energy Commission was used to perform a gamma radiation survey of an extensive area surrounding the Prairie Island Nuclear Generating Plant during September 1971, prior to reactor start-up. The Prairie Island Plant, operated by the Northern States Power Company, is located near Red Wing, Minnesota. The size of the survey area was 800 square miles.

\subsection{ARMS Program}

The present survey was made as part of a continuing nationwide ARMS program started in 1958 to monitor radiation levels surrounding facilities producing or utilizing radioactive materials. This is the first such survey performed in the Prairie Island area.

The detection system on board the aircraft collects gamma-ray gross-count and spectral data on each flight line of the survey. The gamma radiation and aircraft position information are processed by a computer into an isoexposure contour map of the area surveyed.

\subsection{ARMS Equipment and Procedures}

The ARMS aircraft and its on-board radiation detection equipment were used in the survey. Since the ARMS equipment and procedures have been discussed in detail elsewhere (Ref. 1), they will only be described briefly here.

The ARMS surveys are llown in a Beechcraft Twin Bonanza at an altitude of 300 to 500 feet above terrain and a ground speed of about $140 \mathrm{knots}(235 \mathrm{ft} / \mathrm{sec}$ ). The ground position of the aircraft and its altitude above terrain are measured and recorded every other second by a radar navigation computer system. The position and altitude measurements are accurate to $\pm 350 \mathrm{ft}$ and $\pm 5 \mathrm{ft}$, respectively.

A typical flight pattern consists of a series of parallel lines spaced one nautical mile (6080 feet) apart, covering all of the land area within a twelve and one-half nautical mile radius of the facility. 
At an altitude of 500 feet the field of view of the detectors is approximately $1 / 4$ mile wide for a mean gamma energy of naturally occurring isotopes.

The aerial radiation measurements are of two distinct types, made simultaneously: (1) gross gamma count (intensity) measurements and (2) gamma spectral measurements. The detector system consists of an array of fourteen $4 \times 4$ in. NaI (Th) scintillation crystals, each coupled to its own photomultiplier assembly. The detector system output is directed both to the gross gamma count computing system and to the multichannel spectrum analyzer. The data collecting system is shown in Figure 1.

The gross gamma count system consists of an amplifierdiscriminator-computer unit that counts and records the total number of gamma-rays of energy greater than $50 \mathrm{keV}$ that are detected during a 1 -second time interval. The gross gamma count rate (number of gamma-rays detected per second) is digitally recorded along with aircraft position and altitude every other second. Aircraft position data are supplied by a track navigational computer and doppler radar. Altitude above terrain is measured with a radar altimeter. As a backup and complement to the digital recording of the gross-count data, a record is made on a continuous strip chart of both gross gamma count rate and radar altitude as a function of distance. Typical gross-count rates for natural background are several thousand per second.

Whereas the gross gamma count data specify the intensity of radiation as a function of position, the gamma spectral data are useful in identifying particular radioactive isotopes. A pulse-height analyzer automatically sorts detected gamma-rays according to energy, thereby generating a number per unit-energy versus energy spectrum. Although gamma rays occur only at well known discrete energies characteristic of the emitting species, air scattering tends to smear the detected distribution. Nevertheless, characteristic peaks that permit isotope identification are readily observable. In wide area surveys the typical acquisition time for a gamma-ray spectrum is several minutes; thus the spectrum represents the average radiological properties of a tract several miles in length. However, if an area of interest is indicated by an increase in the gross gamma count rate, spectral data acquisition times of only a few seconds are used to isolate the area spatially. If further investigation is warranted, a ground mobile unit with equipment similar to that in the aircraft is available to provide greater spatial and energy resolution.

In addition to the equipment just described, the ARMS aircraft also carries an air sampling and analysis system for the measurement of airborne radioactivity. 


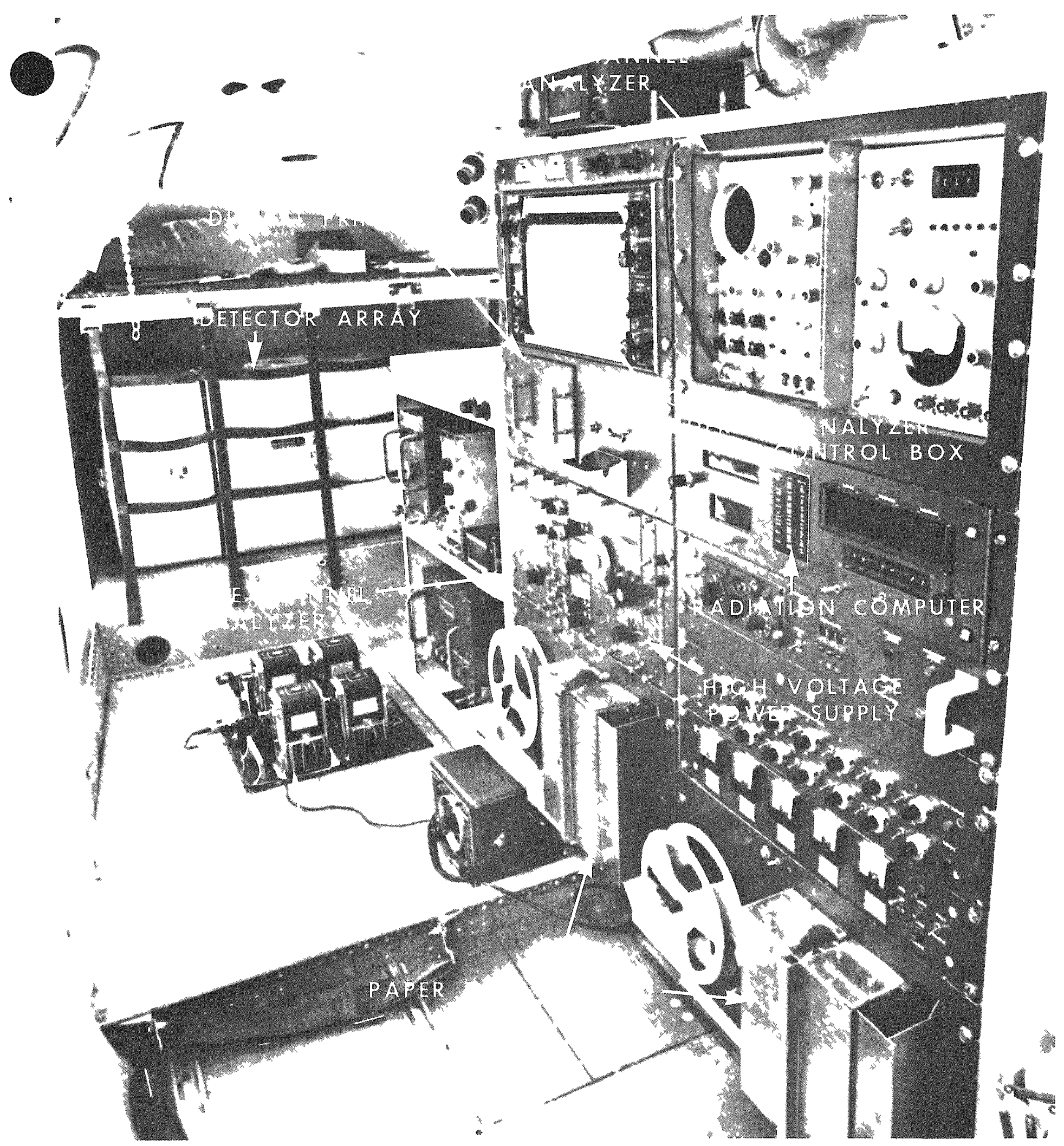

FIGURE 1. View of the interior of the Aerial Radiological Measuring System (ARMS) aircraft showing detector package and electronic data collection system. 
1.4 Reduction and Presentation of Data

The raw data from the gross gamma count and the gamma spectral measurements are permanently recorded on paper tape, which is computer processed and analyzed to characterize the radiological properties of the area surveyed. Using an altitude-dependent conversion factor obtained from prior calibration measurements, the raw gross-count rate is converted to exposure rate $(\mu R / h r)$ at three feet above ground.

The exposure rate conversion factor was obtained from repeated flights 200 to 1000 feet above terrain containing known distributions of natural isotopes. Such conversion factors have proved valid over distributed fission product fields, with a variation of less than $25 \%$. In practice, variations of $2 \mathrm{uR} / \mathrm{hr}$ or greater can be reliably observed in repeated flights over the same area. 


\section{REACTOR AND SITE CHARACTERISTICS}

\subsection{Reactor Characteristics}

The Prairie Island Reactor is located in Goodhue County, Minnesota, three miles northwest of Red Wing.

The principal nuclear contractor is the Westinghouse Electric Company. The facility is operated by the Northern States Power Company.

Table 1 gives the specifications of the reactor facility. At the time of the survey the reactor had not yet commenced operating.

TABLE 1. Reactor facility specifications.

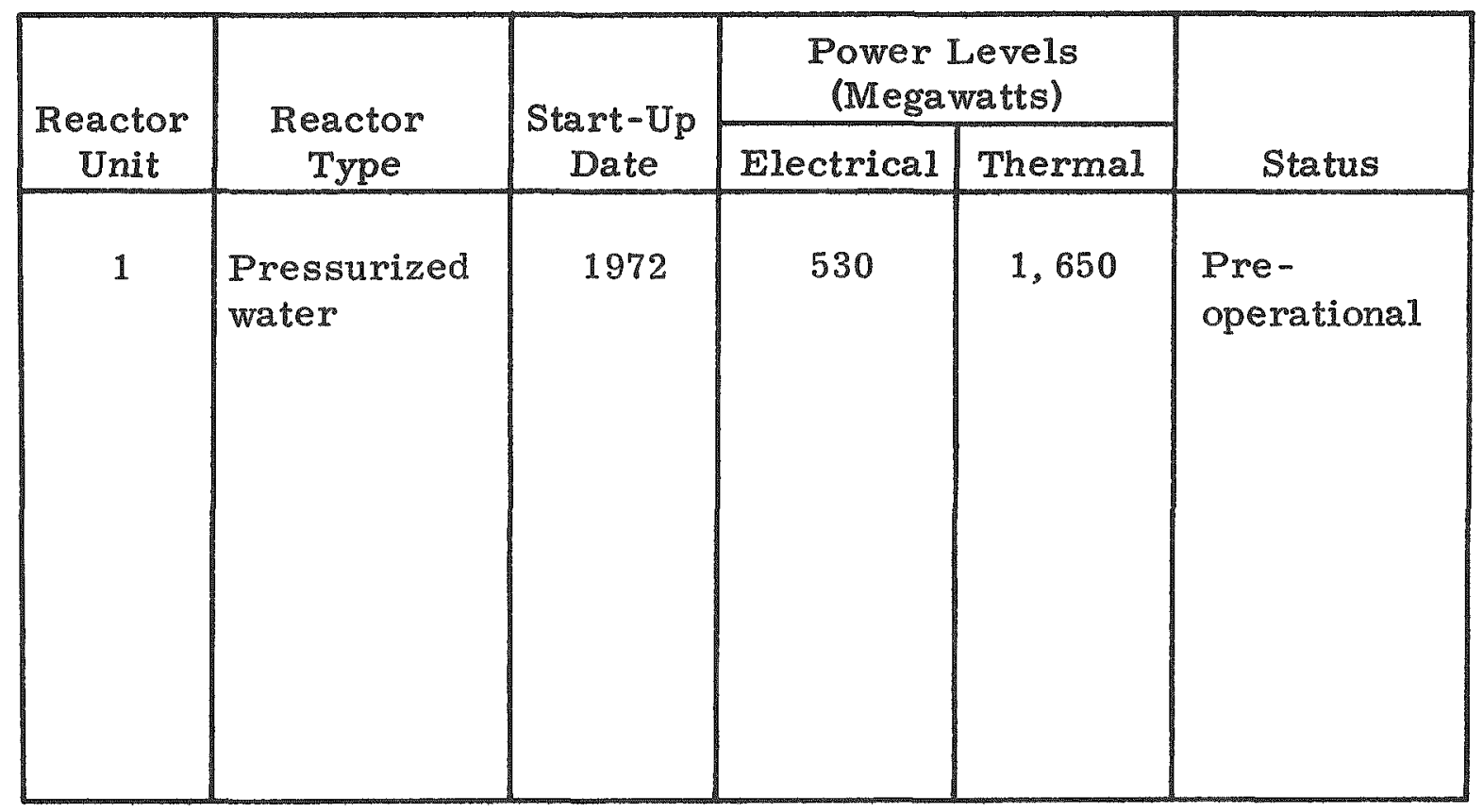




\subsection{Site Area Characteristics}

The survey area is mainly wooded country containing many small lakes. The Mississippi River runs through the center of the area.

Table 2 lists the towns in the survey area with-significant populations, by distance and direction from the reactor site. 
TABLE 2. Principal population centers within the Prairie Island area.

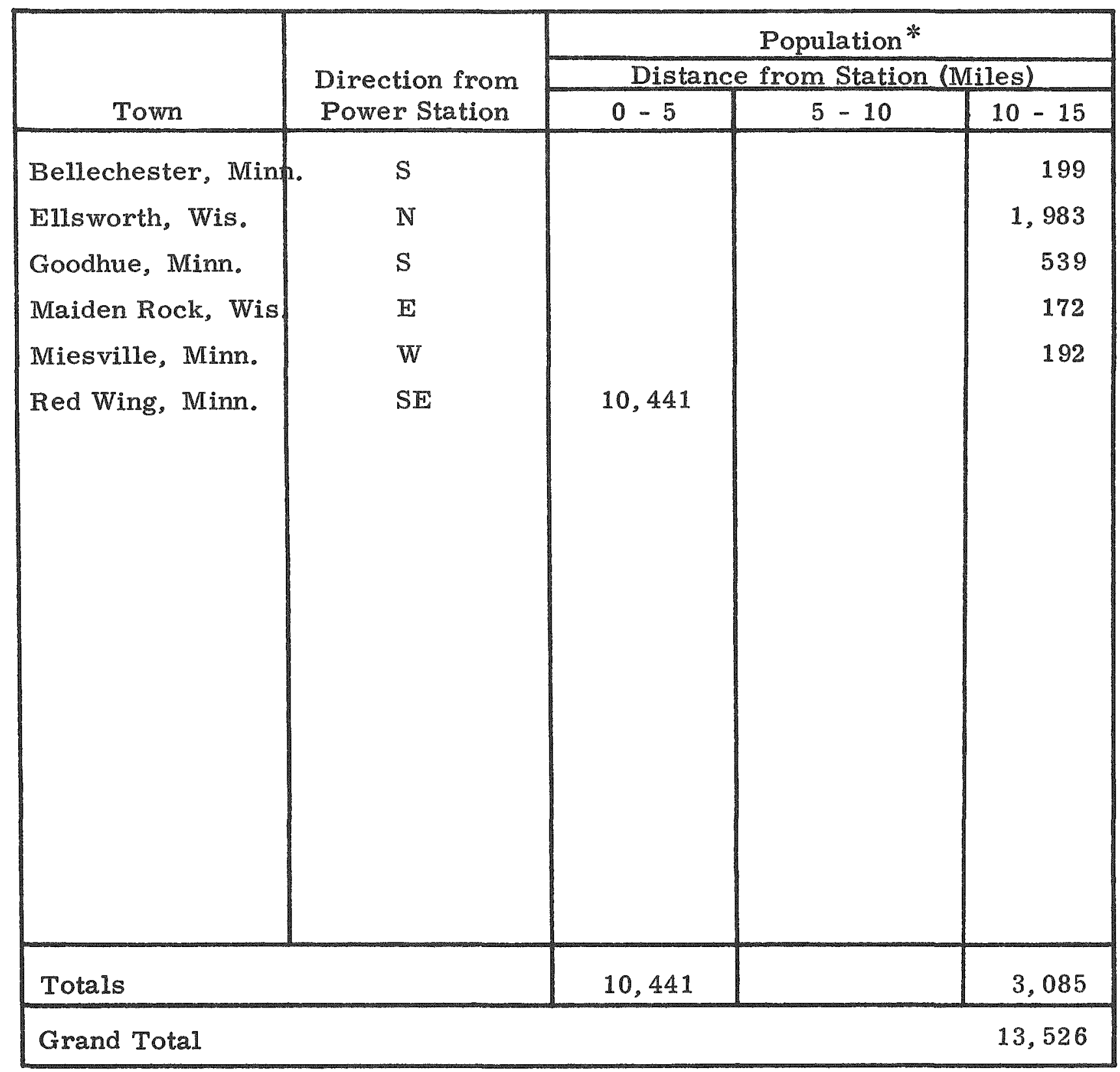

* 1970 census figures (Ref.2). 


\section{SURVEY PLAN}

\subsection{Specification of Flight Lines}

The flight pattern for the Prairie Island survey consisted of 25 flight lines approximately 25 nautical miles long and spaced one nautical mile apart. The lines were oriented in an east-west direction. Radiation data together with aircraft position and meteorological information were collected along each flight line. The area covered by the survey was about 600 square nautical miles, or 800 square statute miles.

\subsection{Coordination with Local Authorities}

ARMS survey missions are conducted under special waiver from the Federal Aviation Administration. The survey plan was discussed with the appropriate General Aviation District Office, and public announcements were published in the local newspapers prior to the survey operation in accordance with the FAA waiver for low-level flights.

The base of operations for the survey mission was Minneapolis, Minnesota. 


\section{RADIOLOGICAL SURVEY}

\section{4. $1 \quad$ Survey Missions}

The aerial survey of the Prairie Island area was conducted on 2, 3, 10, and 11 September 1971. This survey required a total flying time of 18 hours.

Gross-count and spectral data were simultaneously collected at an altitude of 500 feet. Spectra were accumulated over 4 -minute intervals during which the aircraft traveled approximately 12 miles; consequently two spectra per line were collected.

\subsection{Gross-Count Data}

As a first step in the analysis of the gross-count data, the background due to nonterrestrial radiation was subtracted. This background consists of cosmic-ray, aircraft, and airborne radioactivity contributions (Ref. 3). After correction for background, the data were normalized to a standard air mass. The resultant net-count data were then converted to exposure rate in microroentgens per hour ( $\mu \mathrm{R} / \mathrm{hr}$ ) at the 3 -foot level above the ground. The cosmic-ray exposure rate was then added back to the terrestrial exposure rate. Finally, the composite exposure rate data, together with aircraft position information, were processed into an isoexposure contour map for overlay on U. S. Geological Survey topographic maps of the survey area.

An isoexposure map of the Prairie Island area is shown in Figure 2. The data shown on the map include a cosmic radiation contribution of 2 to $4 \mathrm{\mu R} / \mathrm{hr}$. Spatial resolution of the exposure rate data is determined by the field of view of the detector system, which is about $1 / 4$ mile.

\subsection{Spectral Data}

Spectral data were recorded from about 0.03 to $3.0 \mathrm{MeV}$. The recording system was calibrated prior to takeoff with an yttrium-88 source, which emits two prominent gamma-rays of 0.898 and $1.836 \mathrm{MeV}$. The gain for each crystal in the 14 -crystal detector array was set independently. 


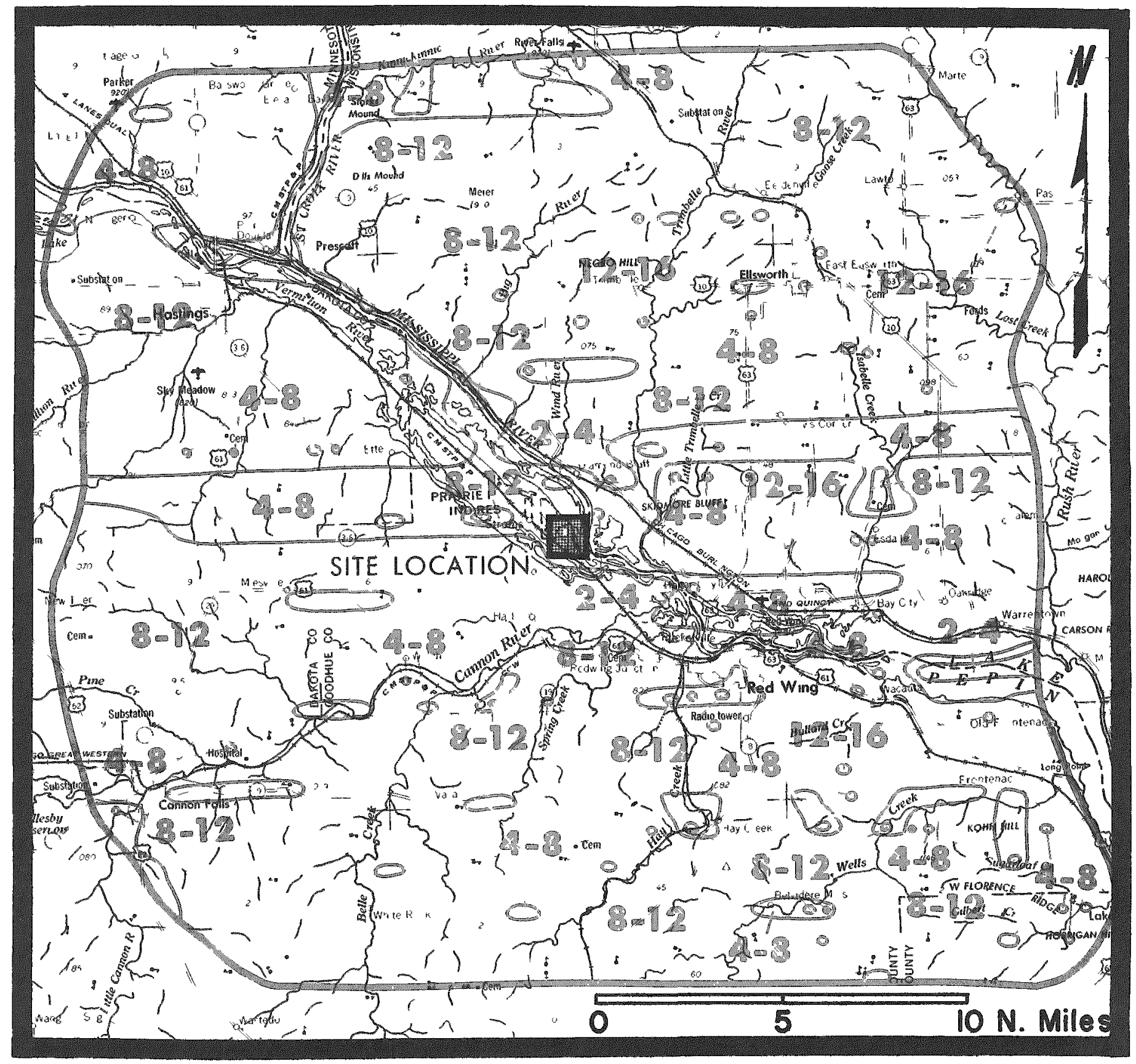

FIGURE 2. Gamma exposure rate contour map of the Prairie Island area, September 1971. (Values shown are in units of $\mu R / h r$. ) 
A spectrum typical of those taken during the survey is shown in Figure 3. Table 3 lists the prominent gamma-ray energies and associated source isotopes identified in the spectrum. Differences in shape between spectra taken over different portions of the survey area are minor, and the isotopes identified in all spectra are the same. Only isotopes consistent with normal background radiation are apparent. 


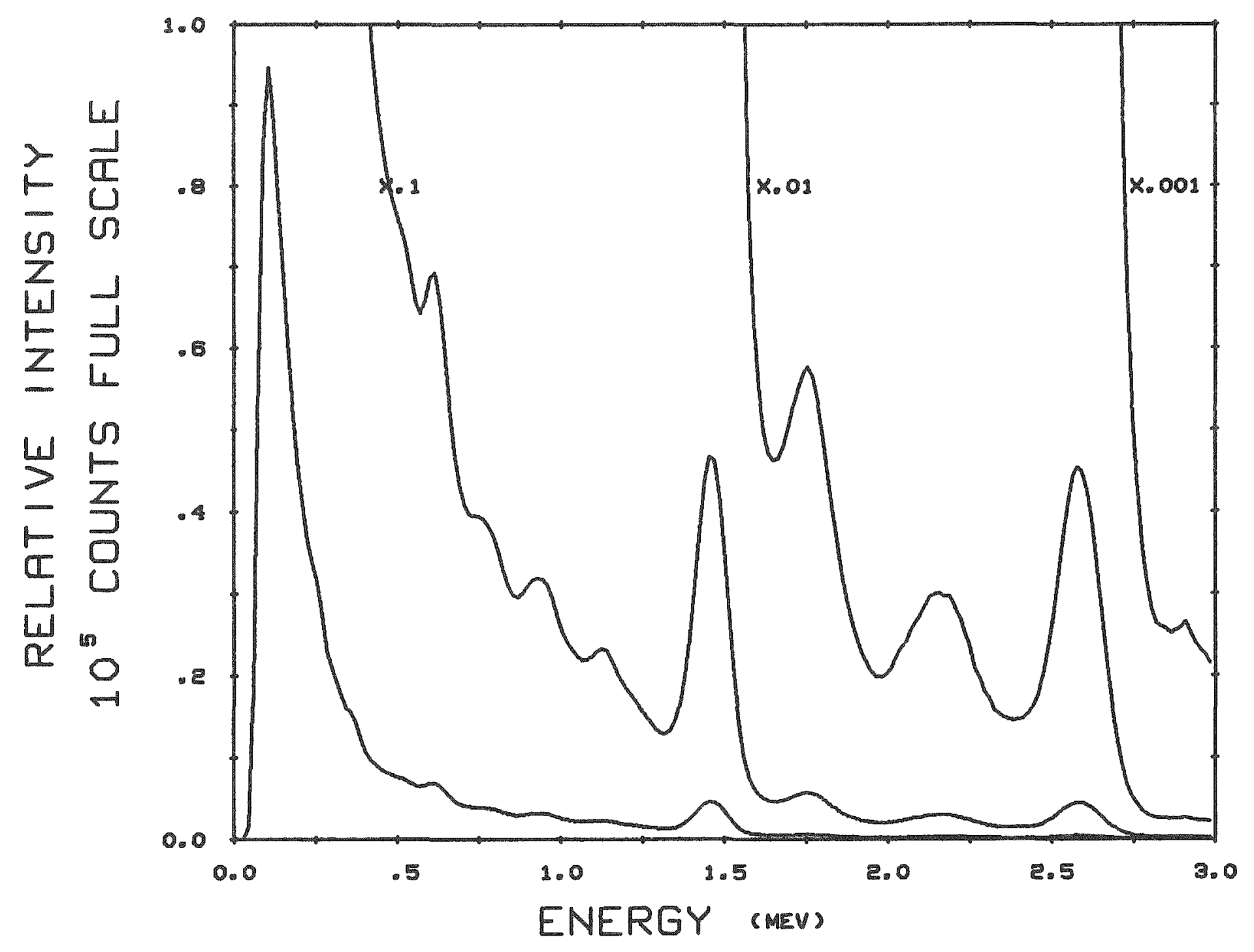

FIGURE 3. Typical gamma spectrum for survey area. 
TABLE 3. Gamma-ray energies and isotopes consistent with spectral data of Figure 3.

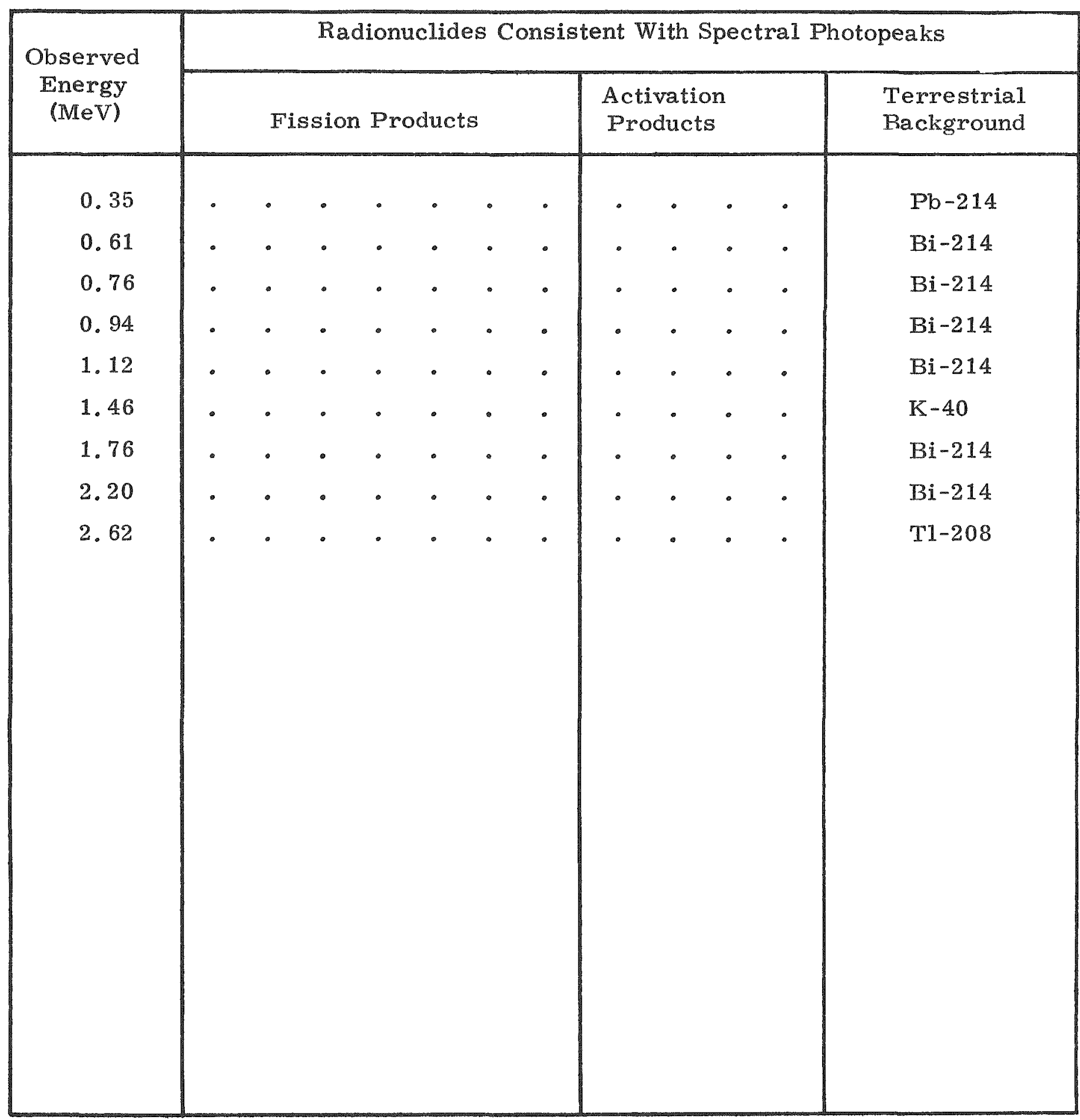




\section{SUMMARY AND CONCLUSIONS}

Since at the time of the survey the Prairie Island reactor had not yet commenced operating, the survey provided a background gamma radiation map of the reactor area. Exposure rates and radioactive isotopes revealed are consistent with normal terrestrial background.

The 3 -foot level exposure rates mapped during the survey were mostly in the 4 to $12 \mathrm{uR} / \mathrm{hr}$ range. 


\section{REFERENCES}

1. "Aerial Radiological Measuring System (ARMS) - Systems and Procedures Employed Through FY71, "AEC Report No. ARMS-71.6, in preparation.

2. 1970 Census of Population, Advance Reports PC(VI)-25 and PC(VI)-51, U. S. Dept. of Commerce, Bureau of Census, Dec. 1970.

3. Burson, Z. G., Boyns, P. K., and Fritzsche, A. E., "Technical Procedures for Characterizing the Terrestrial Gamma Radiation Environment by Aerial Surveys," EG\&G/LVAO Report No. 1183-1559, 1972 . 